\title{
Left Retroaortic Renal Vein and Superior Mesenteric Artery Vascular Lesion Risk
}

\author{
Mikel Gorostidi ${ }^{1 *}$, Cecilia Villalain ${ }^{2}$, Daniel Rodriguez ${ }^{3}$, Arantxa Lekuona ${ }^{1}$, Irene Diez-Itza ${ }^{1}$ \\ ${ }^{1}$ Gyn Onc Department. Hospital Universitario Donostia, San Sebastián, Spain. \\ ${ }^{2}$ Hospital 12 de Octubre, Madrid, Spain. \\ ${ }^{3}$ Radiology Department. Hospital Universitario Donostia, San Sebastián, Spain
}

Corresponding Author: Mikel Gorostidi, Gyn Onc Department. Hospital Universitario Donostia, San Sebastián, Spain

Received Date: June 22, 2021; Accepted Date: August 04, 2021; Published Date: August 23,2021

Citation: Gorostidi M., Villalain C., Rodriguez D., Lekuona A., Diez I. (2021) Left Retroaortic Renal Vein and Superior Mesenteric Artery Vascular Lesion Risk. J. Obstetrics Gynecology and Reproductive Sciences. 5(7): DOI: 10.31579/2578-8965/087

Copyright: ( ) 2021, Mikel Gorostidi, This is an open access article distributed under the Creative Commons Attribution License, which permits unrestricted use, distribution, and reproduction in any medium, provided the original work is properly cited.

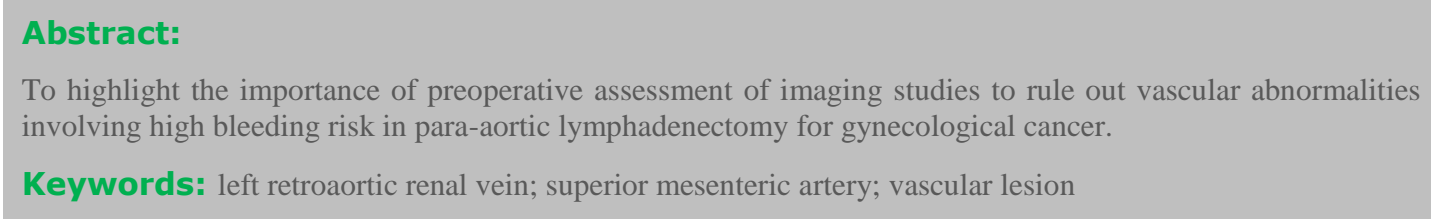

\section{Design:}

Demonstration of the measures to be taken and the areas of maximum danger to avoid an injury, as well as the steps taken to evidence a paraaortic sentinel lymph node, with narrated video footage.

\section{Setting:}

The left retroaortic renal vein has a prevalence of $3 \%$ of cases [2]. Other venous anomalies such as anomalous venous drains mainly in the left infrarenal area, double vena cava, left vena cava, arterial abnormalities, such as APRA (Polar Renal Artery)[3] or anatomical anomalies such as horseshoe kidney can cause severe intraoperative lesions[4]. that it is essential to rule out with a correct preoperative evaluation.

\section{Interventions:}

A 69-year-old woman IAG1 endometrial adenocarcinoma (EC), stratified as low risk EC, was operated by sentinel node (SN) biopsy, laparoscopic total hysterectomy and bilateral salpingo-oophorectomy with frozen section.

Video Legend: The video shows the para-aortic node dissection to identify the para-aortic sentinel node, without identifying the left renal vein, but the upper mesenteric artery, as its upper limit.

https://we.tl/t-oqCZawJ9rw

Dual cervical and transcervical fundal ICG injection for paraortic and pelvic SN detection was performed as part of an ongoing study in our institution already published [1].
The dissection stoped when a thick arterial vascular structure compatible with the superior mesenteric artery was found. There was bilateral SN pelvic detection and aortic detection

Final histological results upgraded the case to high risk EC due to SN positivity: FIGO IIIC2 endometrioid EC G1, $3 \mathrm{cms}$, with no lymphovascular invasion.

\section{Conclusion:}

Multiple vascular anomalies and other non-diagnosed congenital malformations can be identifiable in preoperative imaging tests, but not reported in the radiological report. It is of vital importance the knowledge and preoperative assessment by the surgeon himself to avoid severe intraoperative complications.

None of the authors have any conflict of interest.

IRB approval was not needed for the purpose of this manuscript.

Inform consent was obtained directly from the patient.

\section{References}

1. Ruiz R, Gorostidi M, Jaunarena I, Goiri C, Aguerre J, Lekuona A.(2018) Sentinel node biopsy in endometrial cancer with dual cervical and fundal indocyanine green injection. Int $J$ Gynecol Cancer.

2. Klemm P, Fröber R, Köhler C, Schneider A.(2019) Vascular anomalies in the paraaortic region diagnosed by laparoscopy in patients with gynaecologic malignancies. Gynecol Oncol [Internet]. 96(2):278-82. 
3. Lee WM, Choi JS, Bae J, Jung US, Eom JM.(2018) Encountering the Accessory Polar Renal Artery during Laparoscopic ParaAortic Lymphadenectomy. J Minim Invasive Gynecol [Internet]. 25(1):10-1.
4. Hostiuc S, Rusu MC, Negoi I, Dorobanțu B, Grigoriu M. (2019) Anatomical variants of renal veins: A meta-analysis of prevalence. Sci Rep [Internet]. Dec 25 9(1):10802.
Ready to submit your research? Choose Auctores and benefit from:

* fast, convenient online submission

* rigorous peer review by experienced research in your field

* rapid publication on acceptance

* authors retain copyrights

* unique DOI for all articles

* immediate, unrestricted online access

At Auctores, research is always in progress.

Learn more auctoresonline.org/journals/obstetrics-gynecology-andreproductive-sciences 